\title{
PEMETAAN BUDAYA DI KAWASAN PEDESAAN: STUDI KASUS DESA GIRITENGAH, BOROBUDUR
}

\author{
Titin Fatimah ${ }^{1}$, Nafi’ah Solikhah ${ }^{2}$, Theresia Budi Jayanti ${ }^{3}$ dan Klara Puspa Indrawati ${ }^{4}$ \\ ${ }^{1}$ Jurusan Arsitektur dan Perencanaan, Universitas Tarumanagara, Jl. Let. Jend S. Parman No.1 Jakarta 11440 \\ Surel: titinf@ft.untar.ac.id \\ 2 Jurusan Arsitektur dan Perencanaan, Universitas Tarumanagara, Jl. Let. Jend S. Parman No.1 Jakarta 11440 \\ Surel: nafiahs@ft.untar.ac.id \\ ${ }^{3}$ Jurusan Arsitektur dan Perencanaan, Universitas Tarumanagara, Jl. Let. Jend S. Parman No.1 Jakarta 11440 \\ Surel: theresiaj@ft.untar.ac.id \\ ${ }^{4}$ Jurusan Arsitektur dan Perencanaan, Universitas Tarumanagara, Jl. Let. Jend S. Parman No.1 Jakarta 11440 \\ Surel: klarai@ft.untar.ac.id
}

\begin{abstract}
Indonesia's cultural diversity is an extraordinary potential that needs to be maintained and preserved. Cultural mapping is an effort to document the cultural potential that exists in an area both urban and rural. This research focuses on the mapping process in rural areas in the Borobudur Area, one of the 10 priority tourist destinations established by the Ministry of Tourism. The tourism trend that is developing in Borobudur now is not only focused on the temple, but also to explore the surrounding villages, thus demanding the readiness of each village for the development of sustainable rural tourism. This study aims to find a cultural mapping method that is suitable for rural conditions, by doing a case study in one of the villages in the Borobudur area, which is Giritengah Village, identifying and mapping the cultural potential of the village, so that it can be used as a basis for developing sustainable village tourism planning. This study uses qualitative method with participatory approach. Data was collected through field observations, interviews with community leaders and local residents, literature studies, and Focus Group Discussions. The result of the study shows that cultural mapping in rural areas still follows the steps of standard cultural mapping procedures, however, in the implementation it was adjusted to the conditions of the local community, especially their culture and local wisdom.
\end{abstract}

Keywords: cultural mapping; rural; Giritengah; Borobudur

\begin{abstract}
ABSTRAK
Keanekaragaman budaya yang dimiliki Indonesia merupakan potensi luar biasa yang perlu dijaga dan dilestarikan. Pemetaan budaya merupakan salah satu upaya untuk mendokumentasikan potensi budaya yang ada di suatu tempat/kawasan baik perkotaan maupun pedesaan. Penelitian ini fokus pada proses pemetaan di kawasan pedesaan di Kawasan Borobudur, salah satu dari 10 destinasi wisata prioritas yang ditetapkan oleh Kementerian Pariwisata. Tren wisata yang berkembang di Borobudur saat ini adalah tidak hanya fokus ke candinya, tapi mulai merambah ke desa-desa sekitarnya, sehingga menuntut kesiapan setiap desa untuk pengembangan pariwisata pedesaan yang berkelanjutan. Penelitian ini bertujuan untuk menemukan metode pemetaan budaya yang cocok dengan kondisi pedesaan, dengan mengambil studi kasus di salah satu desa di Kawasan Borobudur yakni Desa Giritengah, mengidentifikasi dan memetakan potensi budaya yang dimiliki desa tersebut, sehingga bisa dijadikan dasar untuk penyusunan perancanaan pariwisata yang berkelanjutan (sustainable village tourism planning). Penelitian ini menggunakan metode kualitatif dengan pendekatan partisipatif. Perolehan data dilakukan melalui observasi lapangan, interview terhadap tokoh masyarakat dan warga setempat, studi literatur, dan Focus Group Discussion. Hasil penelitian menunjukkan bahwa pemetaan budaya di kawasan pedesaan tetap mengikuti langkah-langkah prosedur baku pemetaan budaya, namun dalam pelaksanaan di lapangan menyesuaikan dengan kondisi masyarakat setempat, terutama budaya dan kearifan lokalnya.
\end{abstract}

Kata kunci: pemetaan budaya; pedesaan; Giritengah; Borobudur 


\section{PENDAHULUAN}

\section{Latar Belakang}

Indonesia adalah negara yang kaya akan ragam alam dan budaya yang luar biasa. Data BPS (2010) menyatakan bahwa Indonesia mempunyai 1.340 kelompok etnis, 737 bahasa lokal, 6 agama lokal, serta hampir 245 kepercayaan lokal yang tersebar pada 17.508 pulau-pulau. Kondisi inilah yang menjadikan Indonesia memiliki keanekaragaman pusaka budaya baik yang teraga (tangible) maupun tak teraga (intangible). Bahkan beberapa pusaka atau warisan budaya tak teraga (intangible cultural heritage) yang dimiliki Indonesia sudah mendapatkan pengakuan internasional dari UNESCO. Hal ini menjadi salah satu pendorong untuk melestarikan potensi yang dimiliki. Taylor (2013) menyatakan bahwa keragaman budaya dari seluruh dunia menunjukkan kekayaan pusaka luar biasa yang perlu untuk dihargai. Kesadaran akan pentingnya pelestarian ini membutuhkan suatu alat untuk menginterpretasikan, mendokumentasikan dan menampilkan keragaman budaya kita. Untuk itulah pemetaan budaya dibuat untuk merespon kebutuhan ini. Keanekaragaman budaya menjadi salah satu daya tarik wisata. Data dari Kementerian Pariwisata Indonesia tahun 2015 menyatakan daya tarik atraksi wisaya budaya menempati porsi $60 \%$ dari keseluruhan. Hal ini menunjukkan bahwa potensi budaya di negara kita unggul dan mempunyai peluang tinggi untuk dikembangkan.

Borobudur sebagai salah satu situs pusaka dunia yang sudah diakui oleh UNESCO juga menarik cukup banyak pengunjung dari seluruh dunia. Data kunjungan tahun 2015 menunjukkan angka sekitar 3,5 juta wisatawan (185 ribu di antaranya adalah wisatawan mancanegara) yang berkunjung ke situs bersejarah tersebut. Saat ini Borobudur juga menjadi salah satu dari 10 Destinasi Pariwisata Prioritas yang ditetapkan oleh Kementerian Pariwisata. Oleh karena itu perhatian pemerintah cukup tinggi terhadap perkembangan pariwisata di Borobudur.

Akhir-akhir ini, terjadi tren perkembangan wisata di kawasan Borobudur, yakni mulai berkembangnya wisata alternatif ke desa-desa di sekitar candi Borobudur. Jadi, wisatawan yang datang tidak hanya berkunjung ke candinya, namun juga melakukan jelajah wisata ke desa-desa sekitar yang memiliki beragam potensi. Jelajah wisata desa ini ada yang menggunakan andong, sepeda, atau juga mobil. Fenomena ini cukup menggembirakan, karena dengan adanya kunjungan ke desa-desa sekitar, bisa mengurangi beban kunjungan di candi yang kadang terlalu tinggi, terutama pada masa-masa liburan, padahal kapasitas/daya dukungnya terbatas.

\section{Permasalahan}

Desa-desa di Borobudur sangat berpotensi, namun banyak yang belum berkembang dan terolah dengan baik. Dari 20 desa yang ada di kecamatan Borobudur, baru sekitar 5 desa yang perkembangannya cukup bagus, yang lainnya masih merangkak perlahan atau bahkan jalan di tempat. Banyak potensi desa-desa tersebut yang belum tergali dengan maksimal. Untuk itu dipandang perlu adanya pemetaan potensi yang lebih mendalam di desa-desa di kawasan Borobudur. Sejauh ini masing-masing desa juga belum memiliki Rencana Induk Pengembangan Pariwisata Desa, sehingga diharapkan hasil pemetaan ini nantinya bisa digunakan sebagai acuan untuk menyusunan perencanaan pariwisata yang berkelanjutan.

\section{Tujuan}

Penelitian ini bertujuan untuk menemukan metode pemetaan budaya yang cocok dengan kondisi pedesaan, dengan mengambil studi kasus di salah satu desa di Kawasan Borobudur (dalam hal ini di ambil satu desa sebagai contoh kasus, yakni Desa Giritengah), mengetahui potensi budaya yang dimiliki Desa Giritengah, 
sehingga bisa dijadikan dasar untuk penyusunan perencanaan pariwisata yang berkelanjutan (sustainable village tourism planning).

\section{METODE PENELITIAN}

\section{Pendekatan penelitian}

Penelitian ini menggunakan metode kualitatif dengan pendekatan partisipatif. Dengan demikian selama pelaksanaan pemetaan budaya melibatkan elemen masyarakat terkait sehingga dapat tergali informasi yang lebih dalam sekaligus melibatkan warga sehingga ada ikatan emosional yang terjalin. Harapannya, akan tumbuh rasa memiliki (sense of belonging) terhadap hasil pemetaan dan akan dimanfaatkan dengan sebaikbaiknya sebagai landasan untuk pengembangan berbagai kebijakan ke depannya.

Teknik pemetaan partisipatif biasanya digunakan oleh antropolog budaya, etnobotanis, profesional pembangunan, aktivis komunitas dan lain-lainnya untuk membuat alternatif peta yang memperkuat wacana yang kuat dan memarginalkan secara spasial mereka yang terpinggirkan dengan cara lain juga. Pemetaan partisipatif menyediakan cara untuk memberikan agensi kepada penduduk lokal dalam proses perencanaan, dan untuk menempatkan peta dalam percakapan satu sama lain (Kingsolver et al., 2017)

\section{Metode Perolehan Data}

Untuk melakukan pemetaan budaya yang dimaksud, ada beberapa teknik perolehan data yang ditempuh, yakni sebagai berikut:

a. Observasi lapangan kondisi Desa Giritengah untuk mendata dan memetakan secara lebih detil permasalahan, potensi yang dimiliki baik itu potensi alam, sejarah, budaya, fasilitas, kegiatan ekonomi dan sosial masyarakatnya, dst. Informasi akan direkam dalam bentuk catatan lapangan (field notes) dan foto.

b. Interview terhadap tokoh-tokoh yang tahu dan paham tentang kondisi desanya serta bisa mewakili komunitasnya.

c. Studi literatur dilakukan untuk melengkapi data dari sumber-sumber sekunder seperti arsip-arsip kegiatan, kliping berita, buku-buku, dan berbagai bentuk publikasi lainnya.

d. Focus Group Discussion dilakukan beberapa tahap untuk mengindentifikasi potensi dan permasalahan bersama-sama, sekaligus sinkronisasi dan verifikasi data yang diperoleh dari observasi lapangan.

\section{KAJIAN TEORI}

\section{Pemetaan Budaya}

Pemetaan budaya adalah sebuah pendekatan sistematis untuk merekam dan menampilkan informasi yang menggambarkan karakter dan signifikansi budaya dari sebuah tempat secara terintegrasi (Pillai, 2013). Pemetaan budaya telah dinyatakan oleh UNESCO sebagai sebuah alat dan cara yang krusial dalam mempertahankan/melestarikan aset budaya dunia, baik yang teraga (tangible) maupun yang tak teraga (intangible).

Taylor (2013) menyatakan bahwa budaya yang berkelanjutan (cultural sustainability) bisa diwujudkan dengan menghubungkan manusia terhadap alam dan pusakanya/heritage — atau disebut sebagai cultural landscape — dan menjadi bagian dari upaya menjaga, melestarikan, merencanakan, dan membangunnya secara keberlanjutan dengan menambah nilai sosial dan ekonomi untuk masyarakat. Jadi, esensi dari 
pemetaan budaya adalah melalui riset yang melibatkan keberagaman komunitas, potensi budaya dapat teridentifikasi dan direkam, meliputi komponen fisik maupun aspek intangible yang berhubungan dengan memori, makna dan nilai.

Pemetaan budaya dilakukan dengan melibatkan komunitas lokal dengan mengidentifikasi dan mendokumentasikan potensi budaya lokal yang ada. Melalui kegiatan riset ini beragam elemen budaya direkam, baik yang tangible (seperti galeri, industri kerajinan, penanda kawasan/landmark, event lokal) maupun yang intangible (seperti memori, sejarah/kisah pribadi, sikap dan nilai). Setelah mengidentifikasi elemen-elemen yang membuat keunikan komunitas, dilanjutkan dengan inisiasi berbagai kegiatan atau proyek untuk merekam, melestarikan dan memanfaatkan elemen-elemen tersebut. Tujuan yang paling utama dari Pemetaan Budaya adalah membantu komunitas menyadari, merayakan, dan mendukung keberagaman budaya untuk pembangunan sosial, ekonomi dan regional (Young Clark, \& Sutherland, 1994).

\section{Prosedur pelaksanaan pemetaan budaya}

Menurut Pillai (2013) pemetaan budaya pada dasarnya terdiri atas 3 tahapan yakni: persiapan (framing of mapping exercise), proses pemetaan (process of mapping), dan evaluasi (evaluation). Tahap persiapan dilakukan sebelum pemetaan dilakukan, antara lain dengan menentukan terlebih dahulu rasional dan tujuannya, menentukan lokasi, mengidentifikasi para pihak terkait (stakeholders) beserta kebutuhannya, menentukan cakupan dan skala, pembiayaan, pihak yang terlibat/bekerja sama, rencana luaran, serta rencana jadwal pelaksanaan. Pada tahap pemetaan, dilakukan proses pengumpulan dan perekaman data. Data mentah dikumpulkan untuk kemudian dianalisis dan divisualisasikan untuk memudahkan pemahaman. Tahap evaluasi, dilakukan penilaian mengenai elemen budaya, karakter dari kawasan yang dipetakan, serta nilai signifikasinya. Penilaian ini juga mencakup pengindentifikasian peluang dan kendala yang dapat digunakan untuk perencanaan strategis dan berkaitan dengan budaya.

\section{Perencanaan berbasis budaya (culture-based planning)}

Kesadaran akan pentingnya pelestarian budaya makin meningkat. Hal ini memunculkan sebuah paradigma perencanaan dan pembangunan yang lebih mempertimbangkan aspek budaya. Perencanaan Berbasis Budaya adalah sebuah pendekatan yang bersifat organis, berbasis tempat/lokalitas, dan memiliki konteks yang spesifik untuk merencanakan dengan menggunakan budaya lokal sebagai sumber daya untuk ekonomi dan pembangunan kota (Pillai, 2013). Untuk mendukung terwujudnya Perencanaan Berbasis Budaya, dibutuhkan proses panjang yang komprehensif. Pemetaan budaya sebagai sebuah langkah awal dari sebuah proses perencanaan, adalah sebuah alat (tool) dan metode yang berpotensi kuat untuk memfasilitasi perekaman dan pendokumentasian sistem, sumber daya yang dimiliki oleh masyarakat dalam suatu area.

Gambar 1 berikut menggambarkan pendekatan untuk perencanaan budaya. Pada dasarnya proses perencanaan dibagi menjadi 2 tahap, yakni: tahap 1 memahami site, tahap 2 menyusun perencanaan terpadu. Pemetaan Budaya berada pada tahap 1 langkah ke-2 setelah berkomunikasi dengan masyarakat dan pemangku kepentingan. Dengan demikian bisa dikatakan bahwa Pemetaan Budaya merupakan satu langkah fundamental yang memegang peranan sangat penting untuk melakukan sebuah perencanaan. 


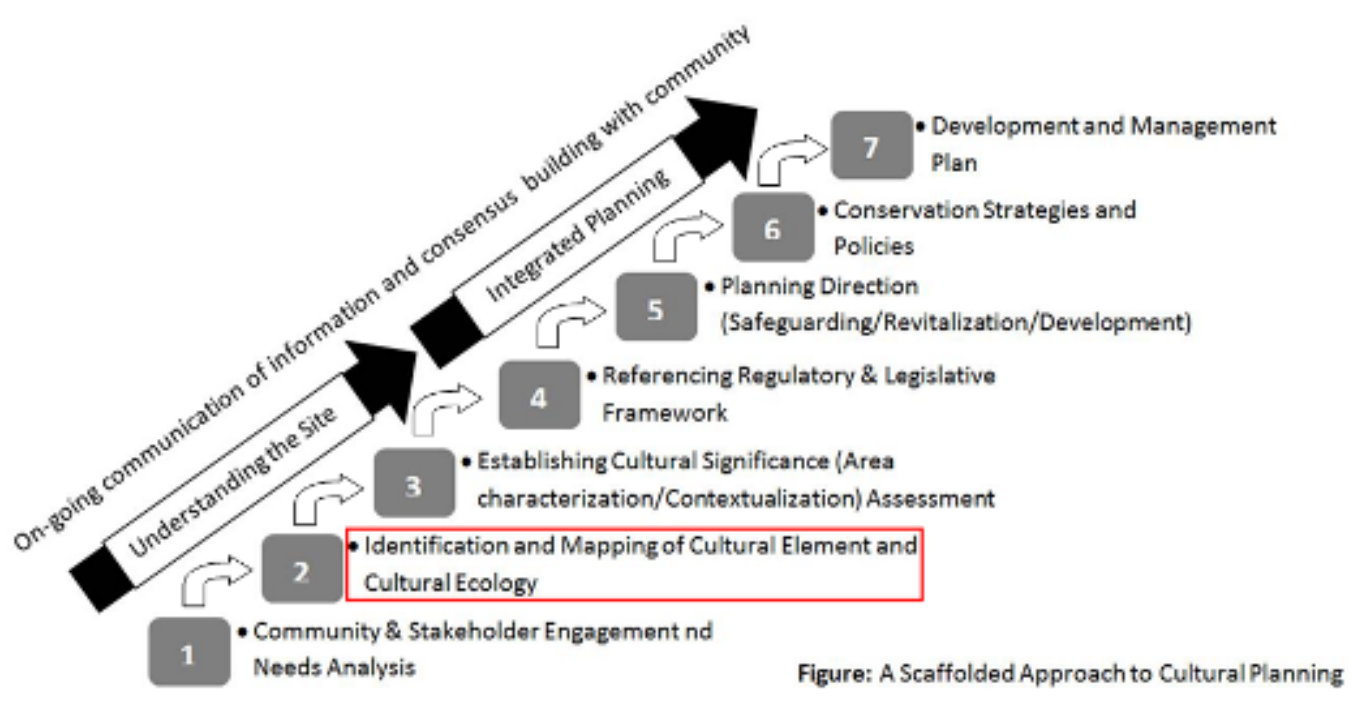

Gambar 1. Pendekatan untuk Perencanaan Budaya (Pillai, 2013)

Ketertarikan dalam perencanaan berbasis budaya telah meningkat di seluruh dunia selama 30 tahun terakhir. Sejumlah buku pegangan dan alat bantu telah dirilis di AS, Kanada, Inggris, Australia dan berbagai belahan dunia lainnya untuk mendukung para pemimpin masyarakat dan pembuat kebijakan untuk memahami relevansi perencanaan budaya bagi pemerintah daerah dan untuk memberikan panduan tentang bagaimana melanjutkan keterlibatan dalam proses perencanaan budaya tersebut (Assuma, 2014)

\section{HASIL DAN PEMBAHASAN}

\section{Perkembangan terkini Kawasan Borobudur}

Kawasan Borobudur merupakan kawasan yang memiliki potensi cukup signifikan dan masuk dalam Kawasan Strategis Pariwisata Nasional (KSPN). Selain itu, Borobudur sebagai salah satu dari 10 destinasi pariwisata prioritas secara nasional membuatnya memiliki posisi yang cukup penting untuk diperhatikan perkembangan pariwisatanya. Kanki et.al (2015) dan Taylor (2003) menyebutkan bahwa desa-desa dan wilayah di sekitar Candi Borobudur yang dibatasi oleh lima gunung merupakan satu kesatuan utuh yang disebut sebagai Pusaka Saujana Borobudur (Borobudur Cultural Landscape Heritage) yang penting untuk dijaga kelestariannya. Hal ini termasuk juga kehidupan di desa-desa dengan segala tradisi dan budayanya, baik yang berwujud maupun tidak (tangible and intangible).

Kegiatan wisata desa mulai berkembang di kawasan Borobudur sejak tahun 2004, dan kini mulai menyebar ke banyak desa di Borobudur (Fatimah dan Kanki, 2012). Saat ini mulai bermunculan destinasi-destinasi wisata baru yang menawarkan berbagai kegiatan di masing-masing desa, antara lain Desa Agro Candirejo, Desa Tahu Tanjungsari, Desa Gerabah Karanganyar, dst. Desa Giritengah merupakan salah satu destinasi baru yang muncul melengkapi desa-desa wisata yang sudah ada.

\section{Identifikasi Lokasi}

Desa Giritengah berjarak sekitar $5 \mathrm{~km}$ ke arah barat daya dari Candi Borobudur yang merupakan Situs Pusaka Dunia (World Heritage Site). Berdasarkan master plan yang disusun oleh JICA bekerja sama dengan pemerinta RI pada tahun 1979, Desa Giritengah masuk dalam Zona 5 yakni untuk kawasan pendukung/pelindung kegiatan pariwisata (bufferzone) Kawasan Borobudur. Secara administratif, Desa Giritengah dibagi menjadi 6 dusun dan terdiri dari 43 RT dan 12 RW. 
Desa Giritengah yang mencakup luasan 432.245 hektar tersebut memiliki banyak potensi wisata, antara lain: Situs bersejarah Sendang Suruh, Puncak Suroloyo, Punthuk Mongkrong, Gupakan Watu Kendil, Bukit Limasan, pasar tradisional, sentra peternakan lebah madu, padepokan seni budaya, kerajinan topeng kayu, kerajinan anyam bamboo, dan lain-lain.
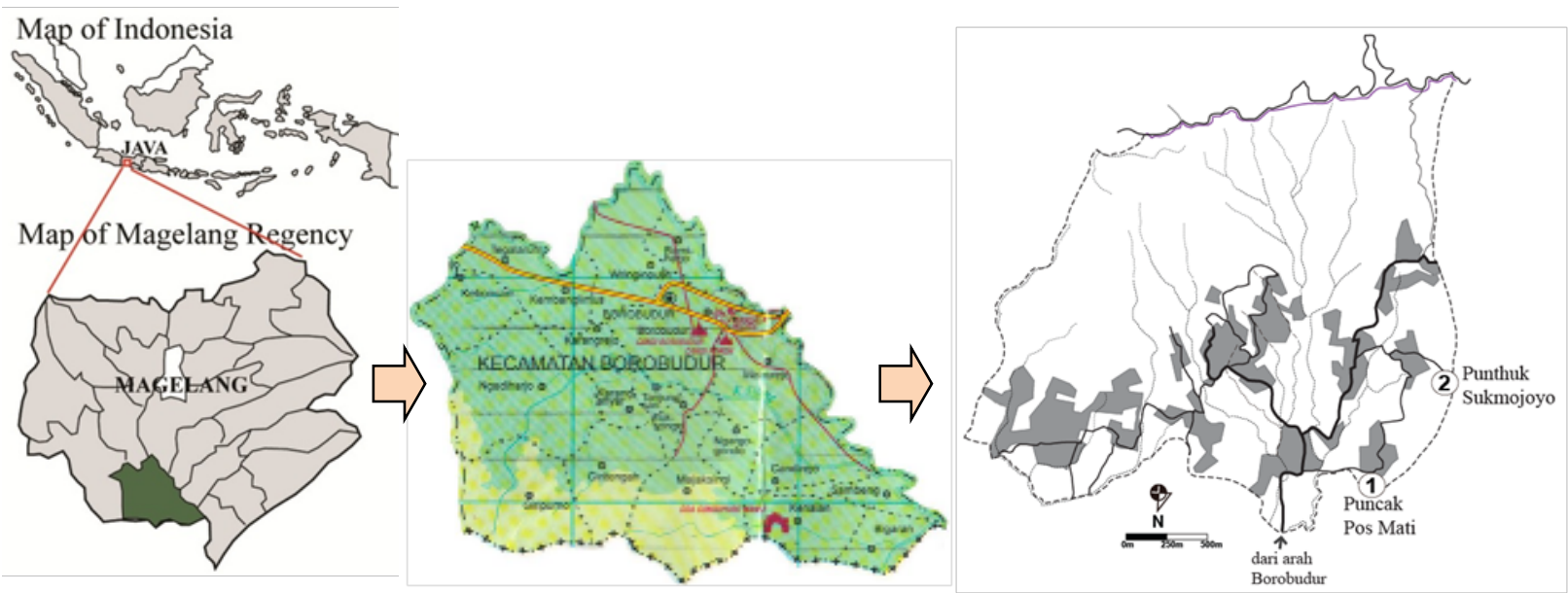

Gambar 2. Peta Lokasi Desa Giritengah (Sumber: Fatimah, 2012)

\section{Pemetaan Budaya di Desa Giritengah}

Kegiatan penelitian dimulai sejak bulan Februari 2018. Sebelum survei lapangan, dilakukan serangkaian persiapan meliputi koordinasi tim, penyiapan materi survei, melengkapi data literatur, serta koordinasi dengan pihak Pengelola Bumdes Giritengah yang menjadi partner dalam pelaksanaan penelitian. Survei lapangan dilakukan melalui observasi dan wawancara, serta dilakukan juga diskusi dengan masyarakat melalui FGD (Focus Group Discussion).

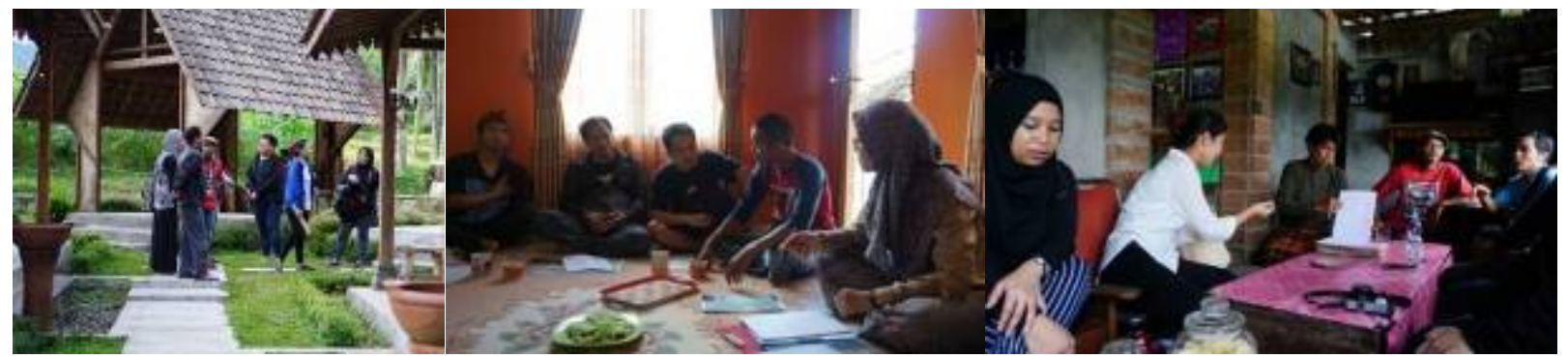

Gambar 3. Survei lapangan dan wawancara

(Sumber: survei lapangan, 2018)

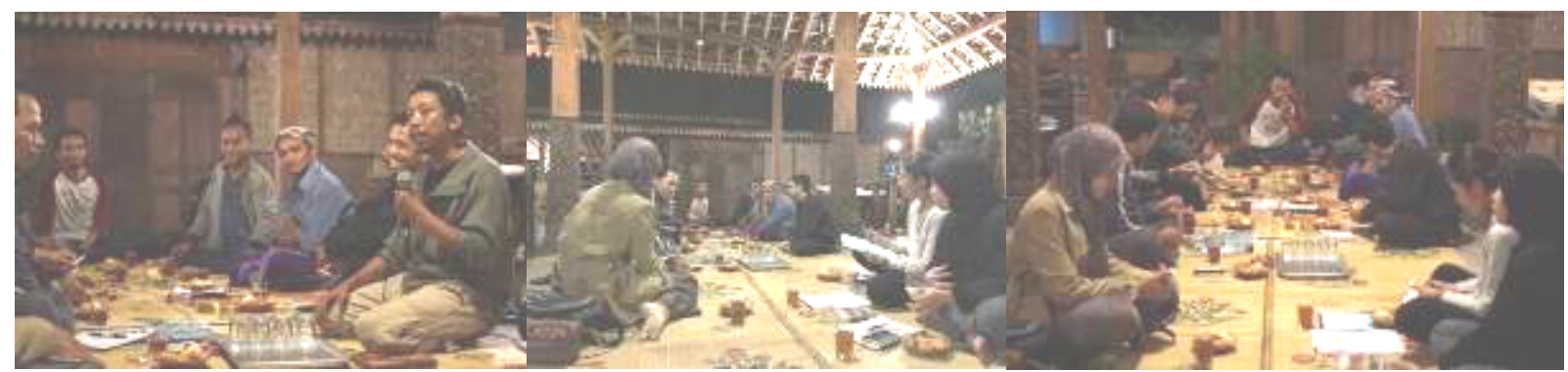

Gambar 4. Suasana Focus Group Discussion bersama tokoh masyarakat Desa Giritengah (Sumber: survei lapangan, 2018) 


\section{Kondisi Geografis}

Secara geografis Desa Giritengah terletak di daerah perbukitan. Terdapat 3 sisi (timur, selatan, dan barat) desa yang di kelilingi perbukitan. Hanya pada sisi utara yang berkawasan datar dan menjadi pintu masuk utama untuk masuk ke Desa Giritengah dari arah Borobudur. Beberapa puncak bukit memiliki pemandangan yang indah dari lansekap Borobudur. Beberapa puncak bukit dapat di kunjungi dengan trekking ke puncak bukit dan berkembang menjadi sunrise/sunset view spot yang menjadi salah satu andalan kegiatan wisata di desa ini.

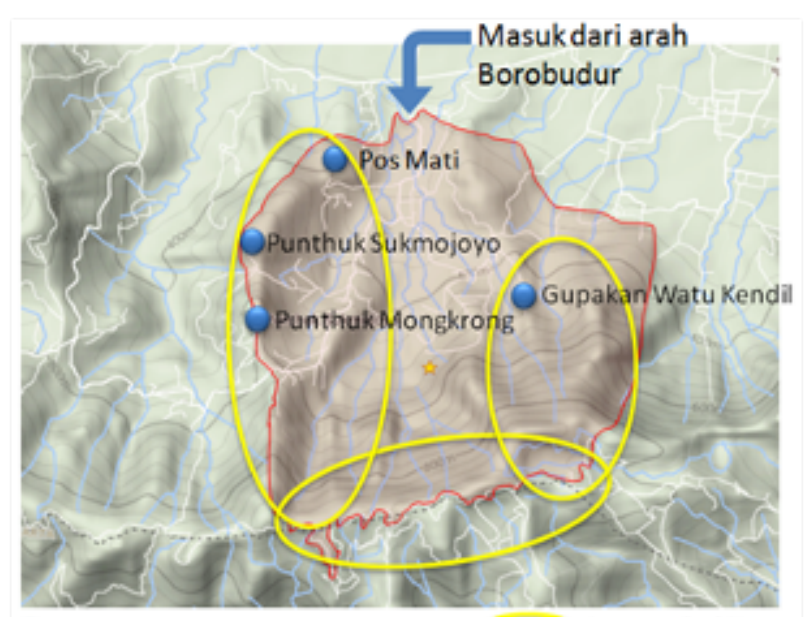

Titik lokasi melihat matahari terbit

Gambar 5. Peta konteks Desa Giritengah yang menggambarkan karakteristik alamnya

(Sumber: Analisis peneliti, 2018)
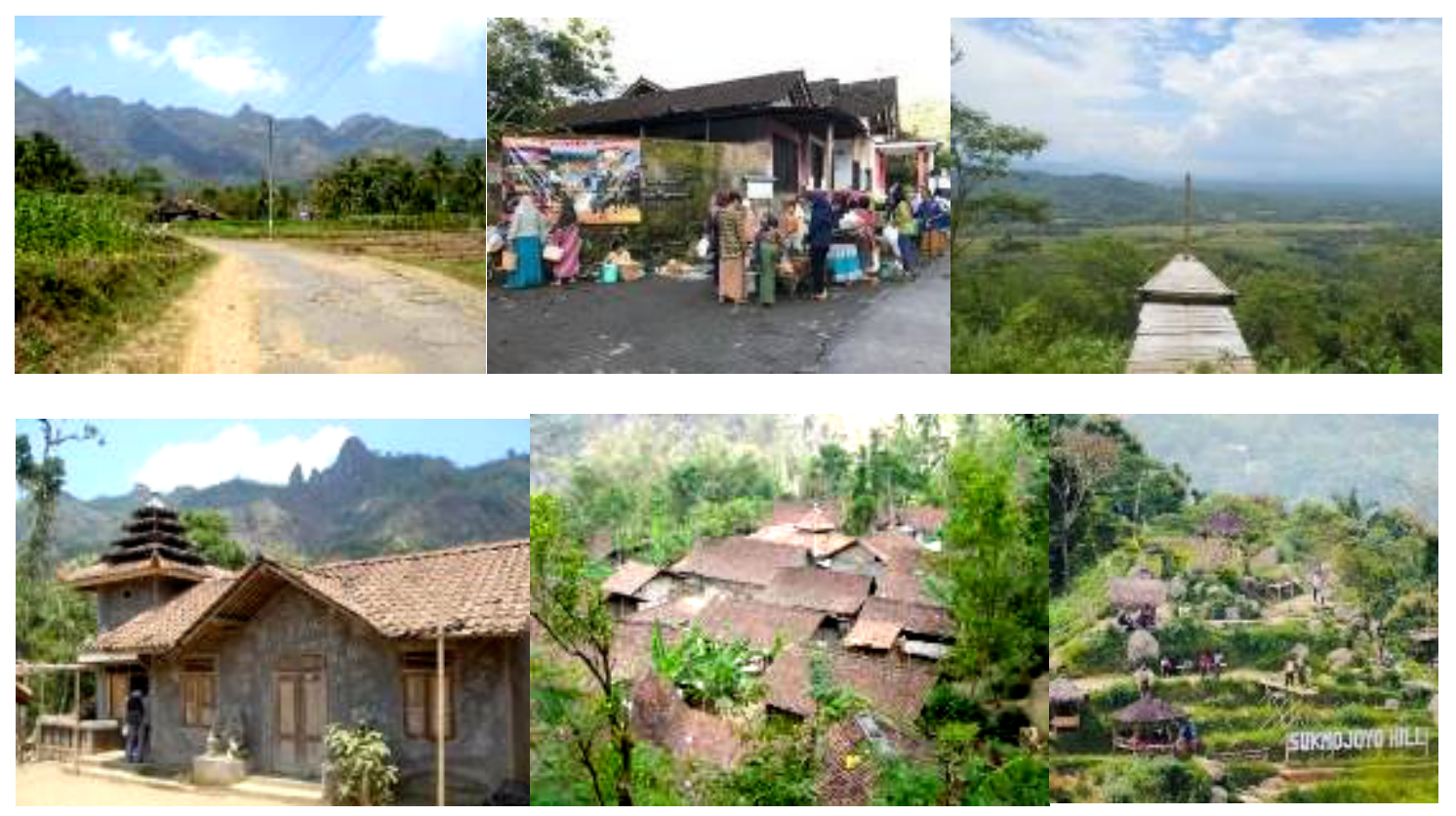

Gambar 6. Suasana desa dan beberapa destinasi wisata desa Giritengah

(Sumber: Survei lapangan dan Pengelola, 2016 dan 2018)

\section{Kondisi Ekonomi}

Masyarakat Desa Giritengah pada awalnya didominasi oleh petani, namun sekarang terjadi pergeseran dengan makin maraknya sumber mata pencaharian lain, seperti buruh perusahaan, pedagang, dan lain-lain. Dari tata guna lahannya, dapat diketahui bahwa area keseluruhan desa didominasi oleh tanah tegalan, yakni 191,65 ha. Fungsi lahan yang lainnya antara lain tanah sawah: 87,30 ha, bangunan dan pekarangan: 10,45 ha, lain-lain: 53,15 ha. 


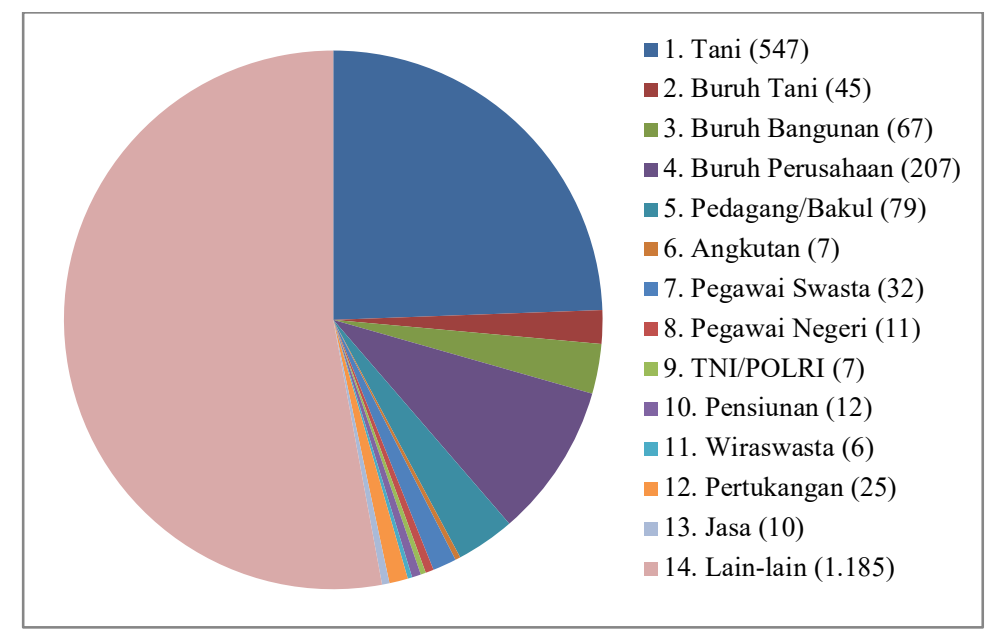

Gambar 7. Mata pencaharian penduduk Desa Giritengah

(Sumber: Monografi Desa, 2016)

\section{Kondisi Sosial Budaya Kemasyarakatan}

Masyarakat Desa Giritengah kebanyakan hidup dalam suasana pedesaan yang masih menjunjung tinggi nilai-nilai tradisi dan budaya lokal. Nilai-nilai kemasyarakatan ini masih kental dan berlaku dalam kehidupan sehari-hari. Budaya Jawa sebagai dasar nilai-nilai sosial dan budaya masyrakatnya masih terlihat, antara lain dalam penggunaan bahasa sehari-hari yang didominasi penggunaan Bahasa Jawa, serta masih berlakunya tradisi seperti mitoni (peringatan 7 bulan kehamilan), slametan (tradisi berdoa bersama agar dikaruniai keselamatan, atau wujud rasa syukur karena mendapatkan sesuatu), wiwit (ritual membawa hantaran makanan ke sawah saat akan panen), dst.

Di Dusun Onggosoro terdapat masyarakat penganut kepercayaan Kejawen yang disebut sebagai Penghayat. Mereka memiliki tempat peribadatan yang dinamai Sanggar Pamelengan, tempat mereka melakukan peribadatan sehari-hari ataupun ritual-ritual khusus seperti saat bulan purnama. Pada suatu masa aliran kepercayaan ini pernah mendapatkan pertentangan dari penduduk Desa Giritengah, namun seiring berjalannya waktu mereka bisa diterima dan hidup berdampingan secara damai dengan anggota masyarakat lainnya.

\section{Kegiatan Parisiwata Desa}

Kegiatan wisata di Desa Giritengah sudah mulai cukup lama. Awalnya dari kunjungan wisatawan di Pos Mati yang merupakan petilasan sejarah Pangeran Diponegoro di sekitar tahun 2004-2005. Setelah itu berkembang cukup signifikan setelah dibukanya beberapa puncak bukit (punthuk) menjadi destinasi wisata untuk view pemandangan dan trekking di sekitar tahun 2015. Secara garis besar, daya tarik wisata di Desa Giritengah bisa dibagi menjadi 4 kategori: wisata alam, wisata sejarah, wisata budaya-religi, dan industri rumah tangga. Dari kegiatan pemetaan yang dilakukan, berikut ini adalah peta yang menggambarkan titiktitik lokasi potensi wisata dan fasilitas yang ada di Desa Giritengah. 


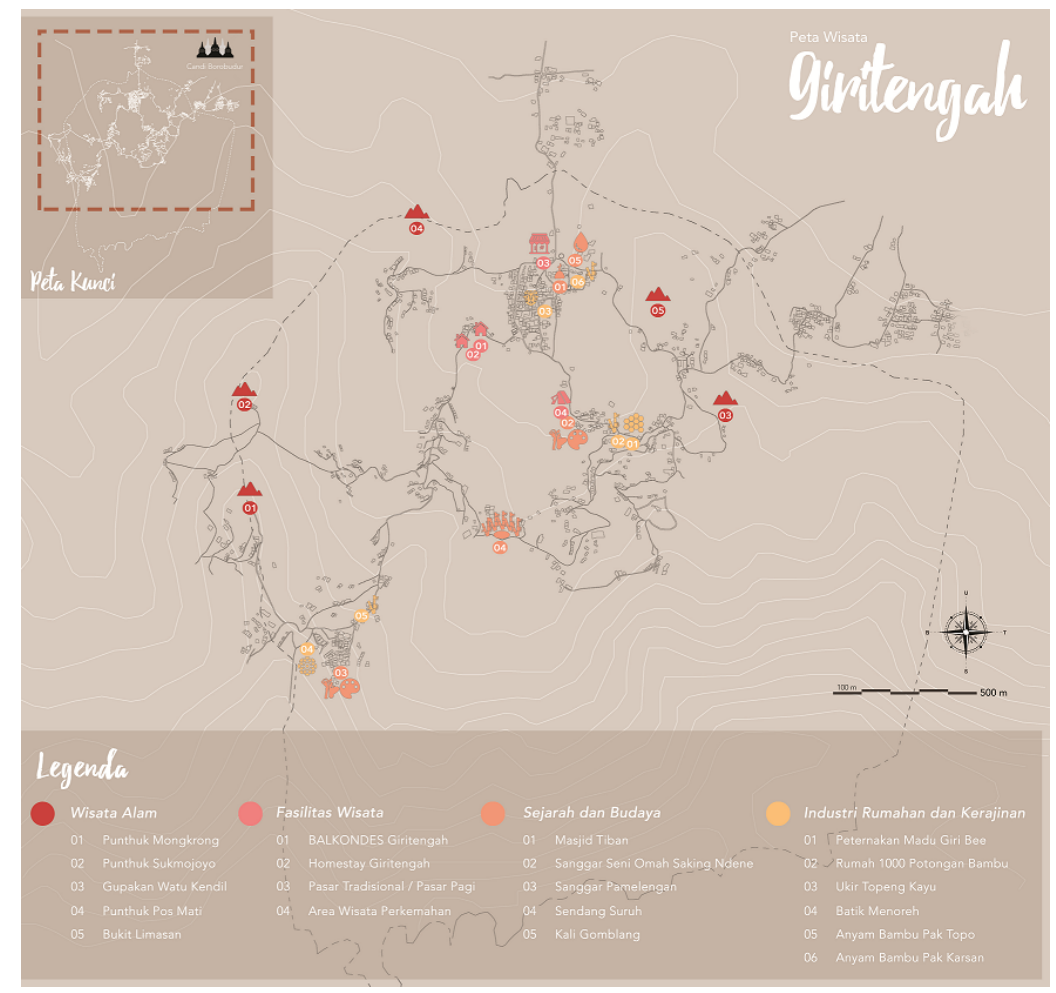

Gambar 8. Pemetaan Destinasi dan Fasilitas wisata

(Sumber: Analisis Peneliti, 2018)

\section{Pemetaan budaya di kawasan pedesaan}

Pelaksanaan pemetaan budaya di kawasan pedesaan tetap mengikuti langkah-langkah prosedural yang baku, yakni ada langkah: persiapan (framing of mapping exercise), proses pemetaan (process of mapping), dan evaluasi (evaluation). Pada langkah persiapan, untuk kasus Desa Giritengah, tim peneliti melakukan komunikasi awal dengan pihak pemerintah desa dan pengelola BUMDes (Badan Usaha Milik Desa) yang bertanggung jawab terhadap kegiatan wisata di Desa Giritengah. Pengelola BUMDes yang melakukan kontak dengan dengan tokoh-tokoh masyarakat dan para pelaku wisata dan pengelola destinasi, untuk perjanjian melakukan wawancara ataupun mengundang untuk hadir di Focus Group Discussion. Dalam pelaksanaan pemetaan di lapangan tim peneliti didampingi oleh perwakilan komunitas lokal yang sekaligus sebagai pemandu.

Dari pelaksanaan pemetaan di lapangan, dapat diketahui bahwa langkah-langkah yang ditempuh sesuai dengan prosedur yang baku. Yang membedakan pelaksanaan pemetaan budaya di kawasan pedesaan adalah dari sisi teknisnya saja. Hal ini dipengaruhi oleh karakteristik wilayah dan masyarakat pedesaan yang memiliki kekhasan tersendiri, misalnya dalam melakukan wawancara atau interaksi dengan masyarakat tim peneliti berusaha untuk menyesuaikan dengan adat-istiadat setempat.

\section{KESIMPULAN}

Pemetaan budaya di kawasan pedesaan berguna untuk mengidentifikasi dan memetakan aset-aset budaya di desa terpilih. Pemetaan meliputi aspek sosial-budaya, ekonomi dan lingkungan. Data hasil pemetaan kemudian dianalisis, untuk digunakan sesuai keperluan, antara lain menentukan strategi pengembangan desa ke depannya. Pemetaan budaya di kawasan pedesaan tetap mengikuti langkah-langkah prosedur baku pemetaan budaya, namun dalam pelaksanaan di lapangan menyesuaikan dengan kondisi masyarakat setempat, terutama budaya dan kearifan lokalnya. 


\section{UCAPAN TERIMA KASIH}

Penelitian ini terlaksana atas dukungan dana hibah penelitian skema PDUPT (Penelitian Dasar Unggulan Perguruan Tinggi) yang diselenggarakan oleh Direktorat Riset dan Pengabdian Masyarakat, Direktorat Jenderal Penguatan Riset dan Pengembangan, Kementerian Riset, Teknologi dan Pendidikan Tinggi, sesuai dengan Kontrak Penelitian Tahun Anggaran 2018 Nomor: 010/KM/PNT/2018, 6 Maret 2018, dan SPK nomor 673-SPK-DIR.PPM/UNTAR/V/2018. Terima kasih kami sampaikan kepada DPPM Universitas Tarumanagara atas dukungannya dalam pelaksanaan, Pemerintah Desa serta Pengelola BUMDes Giritengah beserta warga masyarakat yang turut membantu jalannya penelitian di lapangan.

\section{DAFTAR PUSTAKA}

Assumma, V. and Ventura, C., 2014, Role of Cultural Mapping within Local Development Processes: A Tool for the Integrated Enhancement of Rural Heritage, Advanced Engineering Forum, Vol. 11, pp 495-502, ISSN: 2234-991X, Online: 2014-06-06

Fatimah, T, \& Kanki, K, 2012, Evaluation of Rural Tourism Initiatives in Borobudur Sub-district, Indonesia: A Study on Rural Tourism Activities for Cultural Landscape Conservation, Journal of Architecture and Planning, Transactions of AIJ (Architectural Institute of Japan), Vol. 77 No. 673, March 2012

Kanki, K, Adhisakti, L.T. \& Fatimah, T. (eds.) 2015, Borobudur as Cultural Landscape: Local Communities' Initiatives for the Evolutive Conservation of Pusaka Saujana Borobudur, Kyoto: Kyoto University Press

Kingsolver, A. et al., 2017, Cultural and Participatory Mapping in Brunn, S.D. and Dodge, M. (eds.), Mapping Across Academia, Dordrecht, The Netherlands: Springer Science+Business Media B.V.

Pillai, J, 2013, Cultural Mapping: A Guide to Understanding Place, Community and Continuity, Selangor: Strategic Information and Research Development Centre (SIRDC)

Taylor, K, 2003, Cultural Landscape as Open Air Museum: Borobudur World Heritage and Its Setting. Humanities Research Vol. 10 No. 2 (Monuments and Commemorations): pp. 51-62.

Taylor, K, 2013, Cultural Mapping: Intangible Values and Engaging with Communities with Some Reference to Asia. The Historic Environment, Vol. 4 No. 1, April 2013, 50-61

UNESCO Bangkok, Cultural Mapping, http://www.unescobkk.org/culture/tools-and-resources/tools-forsafeguarding-culture/culturalmapping/ accessed on Oct 15, 2018

Young, G; Clarck, J and Sutherland, J, 1994, Mapping Culture. A Guide for Cultural and Economic Development in Communities, Commonwealth Department of Communication and The Arts, Canberra: Australian Government Publishing Service, pp. 1 and 5. 